\title{
NUTRITION COUNSELING IN AN ACADEMIC MEDICAL CENTER ACCORDING TO SOCIOECONOMIC STATUS AND GROCERY SHOPPING CONSUMER BEHAVIOR DECREASED RELATIVE FAT MASS IN BREAST CANCER SURVIVORS
}

\author{
AnA T. LIMON-Miro* AND ANdrea GARCIA-PAdilla \\ Department of Chemical and Biological Sciences, Universidad de Sonora, Hermosillo, Son., Mexico
}

\begin{abstract}
Background: Body composition assessment in breast cancer survivors (BCSs) is essential to plan feasible dietary strategies for sarcopenic obesity prevention. Objective: Studying the effect of an individualized nutrition intervention according to socioeconomic status and grocery shopping behavior on BCSs relative fat mass (RFM). Methods: BCSs attending an academic medical center were studied; participants saved all 1-week supermarket tickets and answered a grocery shopping consumer preference survey. RFM was assessed at baseline and after the 3-month nutrition intervention. Nutrition plans were based on the dynamic macronutrient meal-equivalent menu method (MEM) and dietary guidelines for BCSs. Results: Thirty-three BCSs completed the study and $91 \%$ of them presented obesity or overweight at baseline. After the intervention, BCSs lost $1.6 \mathrm{~kg}$ ( $p<0.01$ ) of body weight, $1.8 \mathrm{~kg}(p<0.01)$ of RFM, $3 \mathrm{~cm}(p<0.01)$ of waist circumference, and $2.4 \mathrm{~cm}(p<0.01)$ of hip circumference, while no changes were observed in fat-free mass $(p=0.6)$ and arm bone-free muscle area $(p=0.7)$. Conclusions: RFM and body weight in breast cancer survivors decreased after an individualized nutrition intervention according to socioeconomic status and grocery shopping consumer behavior. Based on the participants' food preferences and consumer behavior, plant-based protein diet plans cost less than the animal-based protein diet plans. (REV INVEST CLIN. 2021;73(3):XX-XX)
\end{abstract}

Key words: Oncology nutrition. Nutrition care process. Body composition. Individualized dietary plan cost. Macronutrient mealequivalent menu method. Registered dietitian nutritionist.

*Corresponding author:

Ana T. Limon-Miro

E-mail: analimonmiro@gmail.com
Received for publication: 12-08-2020

Approved for publication: 26-09-2020

DOI: 10.24875/RIC.20000409

0034-8376 / (c) 2020 Revista de Investigación Clínica. Published by Permanyer. This is an open access article under the CC BY-NC-ND license (http://creativecommons.org/licenses/by-nc-nd/4.0/). 


\section{INTRODUCTION}

Body composition has an increasing interest in oncology for its prognostic role ${ }^{1,2}$. Body weight (BW) and fat mass (FM) gain in breast cancer survivors are a common side effect of adjuvant chemotherapy, regardless of their body mass index (BMI), that can affect their quality of life and both disease-free and overall survival ${ }^{3,4}$. Frequently, BMI is used to classify overweight and obesity in cancer ${ }^{2}$. However, BMl cannot distinguish lean and adipose tissue distribution and has been questioned as a ratio for FM estimation $^{1,5}$. For these reasons, novel and reliable equations validated by dual-energy $\mathrm{X}$-ray absorptiometry (DXA) could be used to assess body composition in adult cancer patients. Such equations have been recently proposed by Heymsfield et al. for skeletal muscle mass $(\mathrm{SM})^{6}$, and by Woolcott and Bergman for relative fat mass (RFM) ${ }^{7}$, additionally validated in Northwest Mexican adults by different reference methods along with DXA ${ }^{5}$. During and after cancer treatment, body composition assessment in breast cancer survivors is essential to design strategies and implement lifestyle interventions to prevent sarcopenic obesity ${ }^{8}$.

According to the American Academy of Nutrition and Dietetics, oncology patients should receive nutrition counseling by registered dietitian nutritionists (RDNs) throughout the nutrition care process to prevent malnutrition and sarcopenic obesity ${ }^{9}$. However, diet costs can be considered a potential barrier related to healthy eating ${ }^{10}$. Identifying affordable and appealing nutrient-rich foods should be a priority when designing dietary plans for cancer patients ${ }^{8,11}$. The dynamic macronutrient meal-equivalent menu method (MEM) offers RDNs a systematic way to calculate energy and macronutrient content to design individualized nutrition plans considering standard food servings, population-specific dietary guidelines, and individual socioeconomic, educational, occupational, and cultural characteristics ${ }^{12}$. Still, information regarding grocery shopping behavior in breast cancer survivors, as well as of the costs of specialized dietary plans and their feasibility in oncology patients, is limited. Therefore, our objective was to study the effect of an individualized nutrition intervention according to socioeconomic status and grocery shopping behavior in breast cancer survivors' RFM.

\section{METHODS}

\section{Ethics, study design, and participants}

The research protocol was reviewed and approved by the University of Sonora Ethics and Research Committee. This research has been conducted in full accordance with ethical principles, including the World Medical Association Declaration of Helsinki ${ }^{13}$. This is a non-randomized pre-post study, conducted in the Nutrition Area of an academic medical center in Sonora, Mexico, between November 2014 and 2017. This program emerged as an initiative within the university medical center to improve breast cancer survivors' quality of life and decrease their risk of tumor recurrence, lymphedema, and mortality. The program offers free cancer-related supportive health care to patients with breast malignancies. Depending on the patient's needs, interests, identified barriers, and goals, the program provides a varied range of supportive care. Women with Stages I to III breast cancer diagnosis, with previous breast surgery, chemotherapy, and radiotherapy treatment completion, were potential eligible participants. In addition, breast cancer survivors willing to pursue an adequate and specialized diet $^{8}$, were invited to participate through social media, television, and radio broadcasts, word-ofmouth recommendations from one participant to another, and institutional run/fitness walk events designed to raise public breast cancer awareness. Reasons for non-participation and dropouts were location, transportation, and time barriers, related to missing nutrition appointments, change of address, city of residence, or contact information. Exclusion criteria included self-medication with nutritional supplements and herbal over-the-counter products, being in active cancer treatment, and an incomplete medical record.

At baseline, a signed consent form was obtained from all participants. Data on age, highest education level completed, occupation, and tobacco and alcohol consumption were self-reported by the volunteers. Women without a menstrual period over 12 consecutive months were considered as postmenopausal. In addition, participants answered the following questionnaires: International Physical Activity Questionnaire (IPAQ) ${ }^{14}$, Malnutrition Screening Tool $(\mathrm{MST})^{15}$, and Subjective Global Assessment (SGA) ${ }^{16}$. Both MST and SGA are validated, easy to apply, and 
suitable screening tools to detect malnutrition risk in cancer patients ${ }^{15-16}$.

\section{Grocery shopping consumer behavior and costs of dietary plans}

Each participant completed a survey that addressed sociodemographic variables, including: if the patient received a salary or income, number of family members living in the household who received a salary or income, total weekly family income, the self-declared amount of money spent weekly on grocery shopping, and grocery shopping consumer's preferences (frequency of visits by supermarket and store type, awareness of price discounts and special sales, and awareness of seasonal fruits and vegetables). Furthermore, participants saved all 1-week supermarket tickets to confirm total food weekly expense. We anticipated that perhaps not all participants could save or have their 1-week grocery tickets. Therefore, if they could not obtain the printed or online tickets, we asked them to record what they bought including the total and individual costs of their grocery purchases. Once we obtained the tickets or food purchases records from the patients, one of the researchers immediately called or went physically to the store to obtain the real individual and total costs based on the patient's record to avoid discrepancies in the product cost as well. Next, this information was classified according to food groups and standard food servings ${ }^{17}$. All information regarding income and grocery expenditure from breast cancer patients were obtained in Mexican pesos (MXN) and subsequently converted into the US dollars (USD) to guarantee a universal currency ${ }^{18}$.

Weekly dietary plans costs were calculated for each participant, based on local market prices from Hermosillo, Sonora, Mexico. Costs were classified according to the following categories for individualized diet menus based on the characteristics of plant-based and animal-based diets and the preference, tolerance, and food access to legumes and dairy products, as follows: (1) plant-based diet plan including legumes and dairy products; (2) plant-based diet plan including legumes without dairy products; (3) animal proteinbased diet plan including dairy products without legumes; and (4) animal protein-based diet plan excluding legumes and dairy products.

\section{Anthropometry and body composition assessment}

At baseline and every follow-up nutrition session, participants' BW was measured on a digital scale (SECA ${ }^{\odot}$ model: $285,0-300 \mathrm{~kg} \pm 0.05 \mathrm{Kg}$, Hamburg, Germany) with light and metal-free clothes, without shoes or breast prosthesis. Standing height $(\mathrm{H})$ was measured using a stadiometer (SECA ${ }^{\oplus}$ model: 285 , range of 30$220 \mathrm{~cm} \pm 1 \mathrm{~mm}$, Hamburg, Germany). Then, BMl was calculated as weight in kilograms divided by height in meters squared and categorized according to the World Health Organization (WHO) classification ${ }^{19}$. Anthropometric measurements were performed by trained RDNs and in accordance with the International Society for the Advancement of Kinanthropometry (ISAK) protocol ${ }^{20}$. Mid-upper arm (MUAC), hip, and waist circumferences (WC) were measured with a metal Lufkin tape and waist-hip ratio (WHR) was calculated as the waist circumference in $\mathrm{cm}$ divided by the hip circumference in $\mathrm{cm}$. Measurement of the triceps skinfold (TSF) thickness was done using a Harpenden Skinfold Caliper (range 0-50 mm; minimum graduation $0.2 \mathrm{~mm}$, England). According to the ISAK protocol, MUAC and TSF were measured in the right arm of each volunteer ${ }^{20}$.

The RFM equation used in this study as a fat mass \% estimate ${ }^{7}$, was then validated in Northwest Mexican adults by DXA, air displacement plethysmography, bioelectrical impedance analysis, and a 4-compartment model ${ }^{5}$. Both $\mathrm{H}$ and WC must be added in meters to the equation (Equation S1) ${ }^{7}$. Participants FM in $\mathrm{kg}$ were obtained from the RFM\% and BW resultant. For SM assessment, we used one of the novel equations for women, recently proposed by Heymsfield et al. and validated by DXA in 12,330 participants $\left(r^{2}=0.89, p<0.0001\right)$ (Equation S2) ${ }^{6}$. Likewise, we used anthropometric measurements to calculate the arm bone-free muscle area for women (Equation S3) ${ }^{21}$.

\section{Nutrition counseling}

Individualized dietary plans for breast cancer survivors were based on WCRF/AICR guidelines ${ }^{22}$, adapting 1.2$1.5 \mathrm{~g} / \mathrm{kgBW} / \mathrm{d}$ of dietary protein, $<30 \%$ of energy $/ \mathrm{d}$ from fat (avoiding trans and saturated fatty acid food sources), approximately $50 \%$ of energy/d from carbohydrate food sources rich in dietary fiber. The diet 
included 5-9 servings of fruits and vegetables per day, rich in $\beta$-carotene and Vitamins $A, E$, and $C$, as well as garlic and cruciferous vegetables for their protective effect against breast cancer recurrence, including antioxidant and antiproliferative activity in breast cancer cells $^{8}$. For breast cancer patients with obesity, adjusted, ideal body weight (AdjIBW) was considered to calculate participants' total protein requirement. Correspondingly, AdjlBW was calculated using ideal BW according to BMI (Equation S4) ${ }^{23}$. Resting energy expenditure was estimated using an algorithm for Mexican population ${ }^{24}$. When appropriate $\left(\mathrm{BMI} \geq 25 \mathrm{~kg} / \mathrm{m}^{2}\right)$, a caloric restriction was considered $(500-1000 \mathrm{kcal} / \mathrm{d}$ ) to avoid BW and FM gain and reduce the metastatic burden in breast cancer patients ${ }^{8,25}$.

The nutrition intervention program was based on the $M M^{12}$. This innovative method provides RDNs with an organized way to calculate macronutrients and $\mathrm{kcal} /$ day into an individualized nutrition plan, providing every patient with interchangeable food choices within each mealtime, all being equivalent in energy and macronutrient content ${ }^{12}$. According to baseline sociodemographic and grocery shopping consumer behavior data and the Mexican Food Equivalent System ${ }^{17}$, standard food servings were set by the RDNs. To increase adherence and economic feasibility to the implemented nutrition plans, RDNs proposed wellknown, affordable, and appealing nutrient-rich foods to each participant. All the meal options suggested by the RDNs were included in the individualized nutrition plan in common agreement with each breast cancer patient. Energy (kcal/d) and macronutrients (g/day) theoretical calculations were within the following acceptable ranges: protein $\pm 1 \mathrm{~g} / \mathrm{d}$, total fat $\pm 1 \mathrm{~g} / \mathrm{d}$, carbohydrates $\pm 2 \mathrm{~g} / \mathrm{d}$, and energy $\pm 15 \mathrm{kcal} / \mathrm{d}^{12}$. Patients were encouraged to consume all the food servings contained in their individual dietary plan. For each follow-up session (every 2 weeks \pm 0.5 week), participants provided a self-reported single item for adherence in a 10-point Likert scale $(0=$ poor adherence and $10=$ full adherence during the preceding period) 26,27 . The nutrition plan was modified and adapted according to the individual's needs in each follow-up session ${ }^{12}$.

\section{Sample size and statistical analysis}

Given the exploratory nature of this study, conducted at the initial stages of a new nutrition area in an academic medical center, an emphasis on descriptive statistics was done, as proportions for categorical variables, while means and standard deviations (SDs) were used for normally distributed continuous variables and medians and interquartile ranges (IQRs) for data not normally distributed. Furthermore, sample size was calculated based on a previous study conducted in Sonoran breast cancer patients undergoing cancer treatment and following an individualized nutrition intervention using the MEM ${ }^{26}$. The SD of the change in the outcome (BW) of the previous study was inserted in the formula to calculate sample size for a before-after study (paired $t$-test) with an independent continuous outcome (Equation S5) ${ }^{28}$. Twentythree participants were required to complete the study. An additional $30 \%$ of expected volunteer loss was calculated, having as a result a total of 30 participants required to enroll in the nutrition intervention until 3 months were completed. The mean cost differences between the four dietary plan categories were analyzed by a one-way ANOVA at a $95 \%$ confidence level. Spearman correlation tests were used to measure the strength and direction of the association between two variables. Differences at baseline and 3 months after the nutrition intervention in body composition determinants were analyzed using Wilcoxon test analysis for continuous variables. A two-tailed $p=0.05$ or less was considered significant. Data were processed using the statistical software $\mathrm{NCSS}^{\circledR}$ 11.0. Version.

\section{RESULTS}

From the total breast cancer population attending the academic medical center, $30 \%$ completed the 3-month nutrition intervention and met the inclusion criteria for analysis (Fig. 1). Estimated sample size was met, regardless of the dropouts due to location, transportation, and time constraints. All breast cancer survivors had undergone surgery, $73 \%$ mastectomy and $27 \%$ quadrantectomy. Sociodemographic characteristics of participants are presented and stratified by family annual income to ensure adequate sample description (Table S1). All participants were post-menopausal; their mean age was 55 years \pm 10 and $30 \%$ corresponded to a middle-upper income level. Furthermore, most participants at baseline had a sedentary lifestyle and a very low risk of malnutrition (Table S1). About $36 \%$ of the volunteers had a job or ran their own business. On average, $2 \pm 1$ family members 
Figure 1. Consolidated Standards of Reporting Trials (CONSORT) flow diagram.

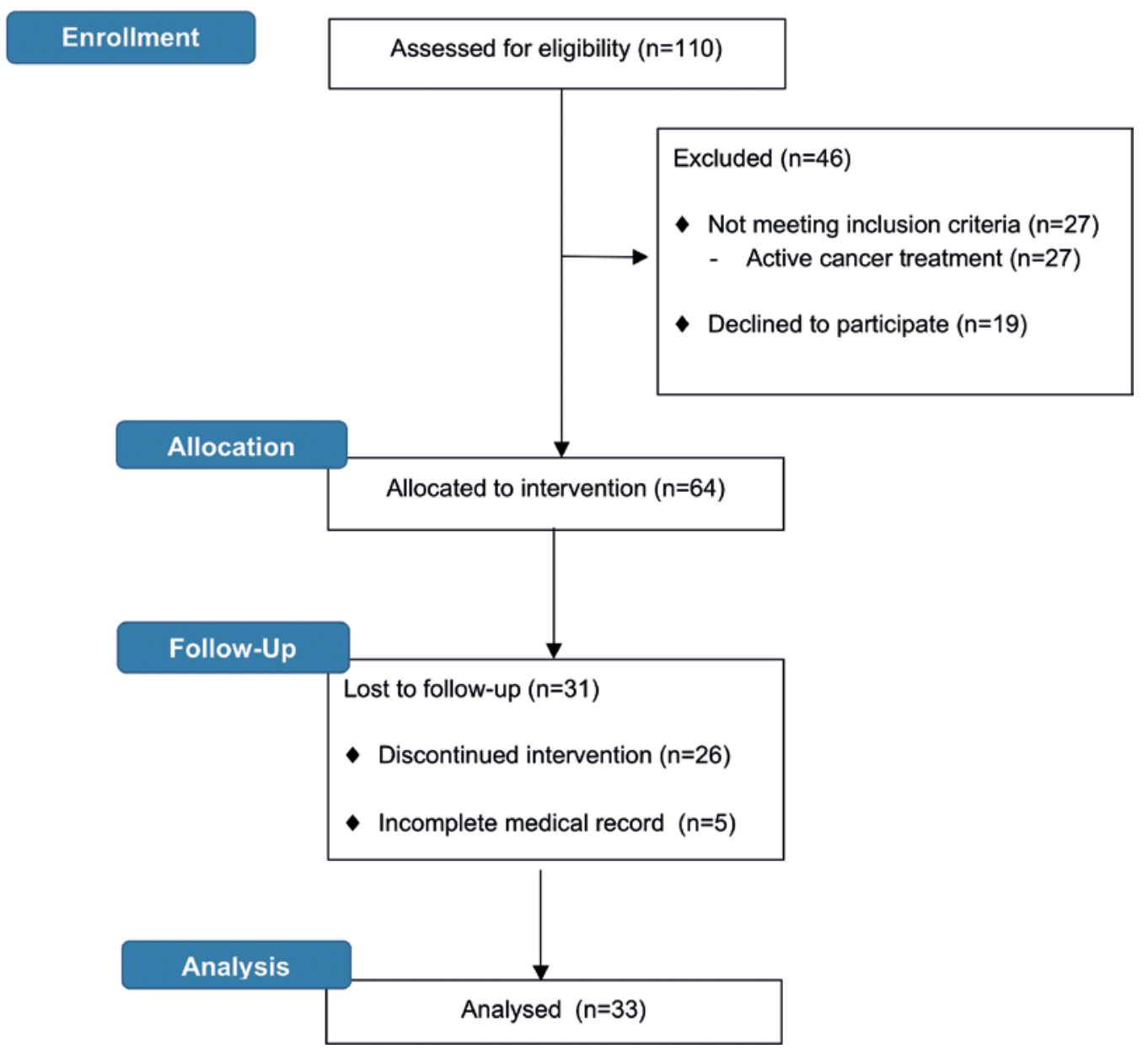

living in the same household periodically received a salary or income. In general, the reported amount of money spent weekly on grocery shopping (\$21 \pm 6 USD) was different to what the participants self-declared $\left(\$ 57 \pm 23\right.$ USD) $\left(r^{2}=0.02, p=0.4\right)$. Only $11.5 \%$ of the volunteers' weekly family income was destined to grocery shopping.

As consumers, participants preferred to shop for groceries weekly (70\%) or twice a month (30\%) at supermarkets. However, the type of grocery store varied according to specific food groups (Fig. 2). Even so, not one volunteer reported making online grocery shopping or requesting a home delivery service. The main characteristic by which participants selected the type of store where they shopped for groceries was their regular prices. Product quality and store location were secondary factors considered by subjects. At the same time, only $35 \%$ of the volunteers shopped for groceries according to seasonal fruits and vegetables, special offers, or discount deals at stores.

The individualized dietary plans contained $6 \pm 0.5$ standardized servings of fruits and vegetables per day ( 3 servings of fruits and 3 servings of vegetables per day) (Table S2). Dietary adherence self-reported by subjects was $8.3 / 10 \pm 0.6$. Food groups servings distribution and average prices, and weekly dietary plan's cost adjusted to $1500 \mathrm{kcal} / \mathrm{d}$, were determined and grouped into 1 of 4 categories according to the patient's preferences, feasibility, and theoretical adherence (Table S2). Diets higher in plantbased sources of protein cost less than animal protein-based diet plans (Table S3). The costs of all dietary meal plan categories were suitable for the amount of money the patients spent on groceries, according to all 1 -week supermarket tickets $\left(r^{2}=\right.$ $0.35, p=0.04$ ). 
Figure 2. Types of grocery stores preferred by breast cancer survivors according to all and specific food groups ( $n=33$ ). (A) all food groups; (B) fruits and vegetables; (C) animal-based proteins; (D) plant-based proteins.

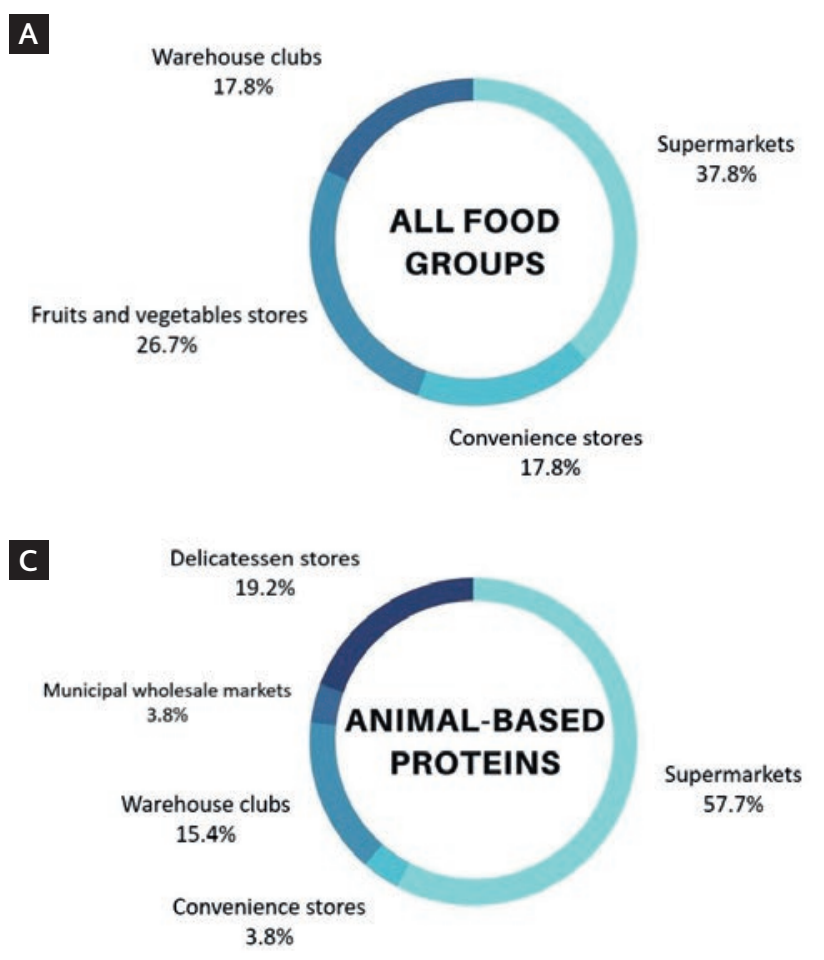

On average, participants estimated resting energy expenditure was $1462 \pm 197 \mathrm{kcal} / \mathrm{d}$, and the estimated total energy expenditure was $2047 \pm 276 \mathrm{kcal} / \mathrm{d}$. When appropriate, a caloric restriction of $538 \pm$ $337 \mathrm{kcal} / \mathrm{d}$ was considered, providing a total of $1509 \mathrm{kcal} / \mathrm{d} \pm 170$ per dietary plan. Based on the participant's BW, $1.3 \pm 0.3 \mathrm{~g} / \mathrm{kg} / \mathrm{d}$ of dietary protein was included in their individualized nutrition plans. When adjusting by AdjIBW in subjects with obesity, they were expected to consume $1.5 \pm 0.2 \mathrm{~g} / \mathrm{kg} / \mathrm{d}$ of protein instead. Mean macronutrient distribution, grams, and energy in the individualized dietary plans were as follows: protein $26 \% \pm 1,97 \pm 11 \mathrm{~g} / \mathrm{d}$, and $390 \pm 46 \mathrm{kcal} / \mathrm{d} ;$ fat $29 \% \pm 2,50 \pm 7 \mathrm{~g} / \mathrm{d}$, and $447 \pm$ $62 \mathrm{kcal} / \mathrm{d}$; and carbohydrates $45 \% \pm 2,169 \pm 21 \mathrm{~g} / \mathrm{d}$, and $676 \pm 85 \mathrm{kcal} / \mathrm{d}$.

At enrollment, obesity and overweight were present in $91 \%$ of the study population. Participants lost $3 \%$ of BW $(p<0.001)$ and $1.3 \%$ of RFM ( $<<0.001)$ after the 3-month nutrition intervention (Table S4). At baseline, breast cancer volunteers' WHR represented an increased risk for poor health outcomes, but not when the 3-month nutrition intervention

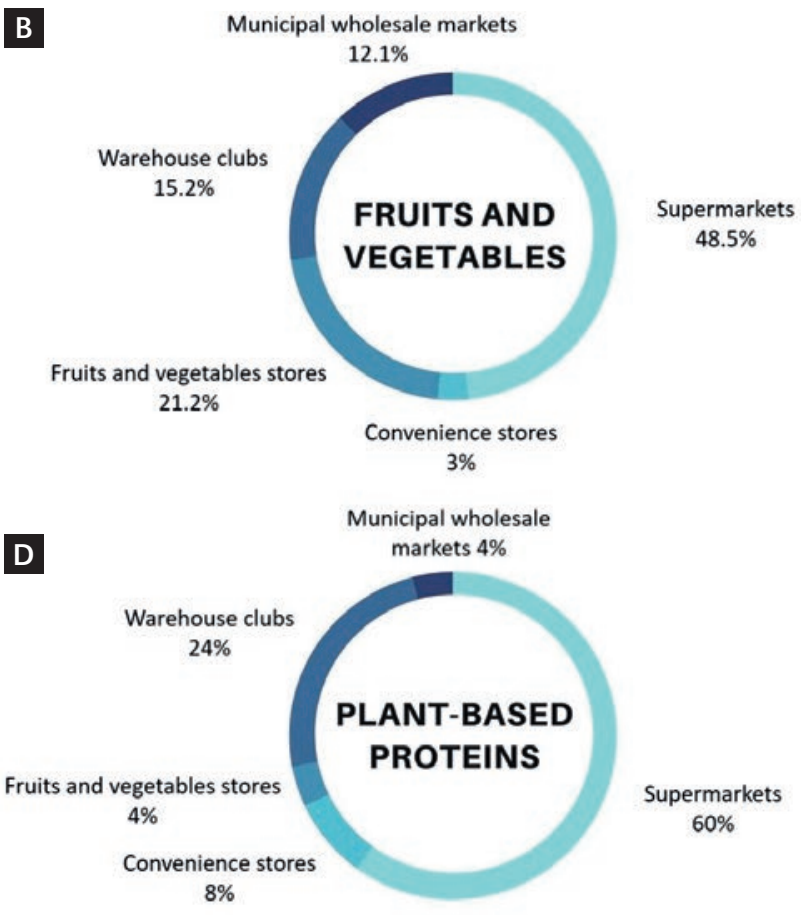

ended (Table S4) ${ }^{29}$. The proportion of participants with a healthy weight increased from $9 \%$ to $21 \%$. Breast cancer survivors with obesity had a greater BW loss $(-3.6 \mathrm{~kg} \pm 0.3, p<0.05)$ compared to participants with healthy $\mathrm{BW}$ or overweight ${ }^{19}$. A decrease in MUAC and TSF, but not in arm muscle area, was observed at the end of the study, meaning that in the arm area, there could have been greater mobilization of fat mass but not of skeletal muscle mass. On the contrary, according to Heymsfield et al. recent equation ${ }^{6}$, skeletal muscle mass decreased during the intervention (Table S4), which may partially compromise the quality of life and prognosis of breast cancer survivors ${ }^{1}$.

\section{DISCUSSION}

Weight loss in breast cancer survivors, particularly fat mass reduction in the abdominal area $^{30}$, as reported in the present study, can improve breast cancer patients' quality of life and decrease mortality, morbidity, and tumor recurrence risk, as described in many studies ${ }^{1,3,30}$. This was not an intervention 
focused only on caloric restriction to promote weight loss. Breast cancer survivors with healthy weight were encouraged to maintain it with special attention to avoid an increase in fat mass. Therefore, it is still important that they adhere to dietary guidelines to avoid sarcopenic obesity and nutrient deficiencies ${ }^{8}$. These are two key reasons why breast cancer survivors with a healthy weight were not excluded from the study. This is the $1^{\text {st }}$ time that RFM is applied in oncology nutrition, with prior validation by four body composition methods in Northwest Mexican adults, as is our study population ${ }^{5}$. RFM has proven to be a better predictor than BMI for body fat percentage ${ }^{5}$, dyslipidemia, and metabolic syndrome ${ }^{31}$, probably due to the incorporation of WC in the equation and its relationship with abdominal and visceral fat ${ }^{29}$. A decrease in RFM may aid for dyslipidemia and metabolic syndrome prevention and should be considered a beneficial health outcome for breast cancer survivors at risk for sarcopenic obesity. Based on our results and previous studies ${ }^{5,31}$, this equation could be used in daily clinical nutrition practice for oncology patients, as a non-invasive, practical, and low cost tool for body composition assessment and follow-up.

This study evaluates dietary intervention exposure, reflected in a decrease in RFM and other body composition changes, with beneficial outcomes for breast cancer survivors, contrary to another observational study carried out in Sonora ${ }^{4}$. Furthermore, breast cancer survivors had a poor prognosis at baseline based on WHR cutoffs ${ }^{29}$ since central obesity increases the risk of mortality, dyslipidemia, and metabolic syndrome in these patients ${ }^{30,31}$. At the end of the study, this risk was no longer prevalent in the participating breast cancer population, also related to our RFM results and better health outcomes. The MEM is a methodological strength of this study because it guarantees strict calculation of energy and macronutrients to match theoretical and actual g/ day and $\mathrm{kcal} /$ day translated into seven interchangeable meal options within each mealtime to provide patients with an individualized, yet flexible, nutrition plan, and also has been recently used in a similar population ${ }^{12,26}$.

People with obesity or overweight are frequently malnourished in the setting of disease, injury, and/or consumption of high-energy poor-quality diets such that overnutrition and malnutrition may coexist. The risk screening procedure is the first mandatory step in any diagnostic process to identify malnutrition and when possible, should always be carried out in breast cancer survivors ${ }^{32}$. Based on our findings, SGA considered well-nourished most of the volunteers in our study population, while they were also classified with obesity or overweight according to BMI. Our results are consistent with findings from the previous studies in breast cancer survivors using SGA to screen malnutrition risk, where obesity and overweight were highly prevalent $(62-86 \%)$ and $71-76 \%$ of participants were classified as well-nourished according to $\mathrm{SGA}^{33-35}$. Then, SGA scores should be taken in the context of other data on patient nutritional status, as in the case of body composition, to provide a more reliable prognosis for patients with obesity and overweight.

Based on our findings, we could notice that dietary protein was not enough to prevent skeletal muscle mass loss. Although skeletal muscle mass was not the main outcome of this study, we did not expect that by following breast cancer patients' dietary guidelines, specifically $1.5 \mathrm{~g} / \mathrm{kg} / \mathrm{d}$ of protein intake ${ }^{8}$, the lean tissue compartment would have decreased. This is one of the limitations of the study that can be improved for future interventions in breast cancer survivors. Physical activity in breast cancer survivors, especially resistance training, is crucial to prevent lean tissue loss $^{3}$. Therefore, future interventions should also consider strategies to maintain or increase muscle mass such as exercise programs and protein supplementation ${ }^{1}$. Thus, breast cancer survivors attending this program should be encouraged to accomplish a physical activity level according to current guidelines $(>150 \mathrm{~min} / \mathrm{wk})^{36}$, and their physical and health condition to decrease lymphedema and injury risk $^{3}$. Furthermore, when possible, skeletal muscle mass should be measured rather than estimated, to avoid over- or underestimation.

The sample size of this study was limited due to its exploratory nature and because it was conducted at the initial stages of the newly created nutrition area in an academic medical center. It was calculated for methodological and ethical reasons, as well as to plan for human and financial resources. Since the estimated sample size was met, the results of this study are statistically valid. It is advisable that future studies focused on body composition 
assessment and follow-up, apply the RFM equation in large study populations within a stronger study design ${ }^{5}$. In our study population, location, transportation, and time constraints appeared to be a problem. Therefore, to reach more breast cancer survivors in the future and prevent dropouts, considering telemedicine and telenutrition, especially homebased programs ${ }^{37}$, could improve cancer patients' participation and accessibility ${ }^{3}$.

In general, healthier diets have been related with higher diet costs per calorie ${ }^{10,11}$. However, our study shows that using methods to individualize dietary interventions, such as the MEM, additionally considering individuals' grocery shopping consumer behavior and socioeconomic status, can overcome common limitations to encourage a healthy and feasible lifestyle among breast cancer survivors. Furthermore, our findings suggest that it is achievable for this population to carry out diet plans high in fruits and vegetables, whole grains, and good sources of protein, when RDNs identify affordable and appealing nutrient-rich foods for inclusion. In this sense, it is imperative for RDNs to integrate all the baseline information provided by breast cancer patients regarding their socioeconomic, educational, occupational, dietary, and cultural background into the dietary plan, through an empathic and systematic way for patients to feel guided into making better decisions within their personal means. By preventing unaffordable nutrition plans and social isolation, dietary plans following the MEM can empower breast cancer patients to make healthy and informed food choices, improving adherence, dietary habits, nutritional status, and overall health ${ }^{12,26}$. This is one of the first studies to identify grocery shopping consumer behavior in breast cancer survivors, to design dietary plans according to the patients' preferences, family income, and energy nutrient requirements ${ }^{38}$.

Breast cancer survivors shopped for groceries mainly in supermarkets rather than in local food markets, making this a risky situation that may compromise their health as well as regional and nationwide food security and economic development. Growth of local food markets is expected to generate public benefits, and identifying situations to adopt broader presence of local food markets is a cost-effective tool for accomplishing policy goals. Therefore, it is essential to propose remedial actions to promote better regulatory practices that can encourage consumers to benefit directly from buying in local food markets and enhance food sustainability ${ }^{39}$. On the other hand, since online grocery shopping has recently increased during the COVID-19 pandemic ${ }^{40}$, future studies should consider diet quality in this setting and online grocery shopping consumer behavior for a more in-depth investigation on individualized nutrition interventions tailored for cancer survivors regarding food costs and affordability.

It was more accurate to obtain information regarding frequency, type of store, and actual grocery expense from the total weekly tickets each breast cancer survivor facilitated to her RDN, instead of relying on what they self-declared. The dietary plans proposed in this intervention, according to the four categories in which they were subclassified, were based on the characteristics of plant-based and animal-based diets as well as the patients' preferences, tolerance, and food access to legumes and dairy products. Still, according to the environment setting of our volunteers and their preferences, plant-based diet plans cost less than diet plans higher in animal protein sources. Plant-based diets including proteins from legumes, nuts, and seeds have recently received much attention as a cost-effective way to improve diet quality within all socioeconomic levels ${ }^{10}$. Nevertheless, other studies have found that adopting a plant-based diet minimally increased food costs in breast cancer survivors ${ }^{38}$ and general population ${ }^{10}$. Breast cancer survivors can benefit in the short and long term by encouraging them to prioritize nutrient rich foods and grocery shopping at local markets, as well as having a more analytical and in-depth nutritional education.

In summary, nutrition counseling according to the MEM, socioeconomic status, and grocery shopping consumer behavior decreased RFM and body weight in breast cancer survivors attending an academic medical center.

\section{ACKNOWLEDGMENTS}

We thank the University of Sonora (UNISON) for supporting the Nutrition Area at the Breast Cancer Patient Navigation Program. Special thanks to the UNISON Cancer Laboratory staff: Carlos Velázquez, 
Alejandra López, Ana Acosta, and Priscila Arámbula; the UNISON Nutritional Health Promotion Center staff: Giovanni Diaz, Teresita Martinez, and Erika Ibarra; and our enthusiastic nutritional sciences undergraduate students for their supportive teamwork: Luisa García, Larisa Trecierras, Fernanda Torres, Diana Flores, Alejandra Velázquez, Carlos López, Sahily Nuñez, Bianca Salazar, Zulueth Soltero, Chrisitan Coronel, and Diana Corella. Our genuine appreciation goes to the volunteers for their valuable time and willingness to participate in this study.

\section{SUPPLEMENTARY DATA}

Supplementary data are available at Revista de Investigación Clínica online (www.clinicalandtranslationalinvestigation.com). These data are provided by the corresponding author and published online for the benefit of the reader. The contents of supplementary data are the sole responsibility of the authors.

\section{REFERENCES}

1. Caan BJ, Feliciano EM, Prado CM, Alexeeff S, Kroenke by computed tomography with survival in patients with nonmetastatic breast cancer. JAMA Oncol. 2018;4:798-804

2. Deluche E, Leobon S, Desport JC, Venat-Bouvet L, Usseglio J, Tubiana-Mathieu N. Impact of body composition on outcome in patients with early breast cancer. Support Care Cancer. 2018; 26:861-8

3. Demark-Wahnefried W, Kenyon AJ, Eberle P, Skye A, Kraus WE. Preventing sarcopenic obesity among breast cancer patients who receive adjuvant chemotherapy: results of a feasibility study. Clin Exerc Physiol. 2002;4:44-9.

4. Cisneros KM, García HA, Romero JE, Torres AG, Juillerat ME Estrada RO, et al. Impacto del tratamiento antineoplásico en el estado nutricional en pacientes con cáncer de mama Nutr Hosp. 2014;30:876-82

5. Guzmán-León AE, Velarde AG, Vidal-Salas M, Urquijo-Ruiz LG, Caraveo-Gutiérrez $L A$, et al. External validation of the relative fat mass (RFM) index in adults from North-West Mexico using different reference methods. PLoS One. 2019;14:e0226767.

6. Heymsfield SB, Stanley A, Pietrobelli A, Heo M. Simple skeletal muscle mass estimation formulas: what we can learn from them. Front Endocrinol (Lausanne). 2020;11:31.

7. Woolcott OO, Bergman RN. Relative fat mass (RFM) as a new estimator of whole-body fat percentage-a cross-sectional study in American adult individuals. Sci Rep. 2018;8:10980.

8. Limon-Miro AT, Lopez-Teros V, Astiazaran-Garcia H. Dietary guidelines for breast cancer patients: a critical review. Adv Nutr. 2017;8:613-23.

9. Macris PC, Schilling K, Palko R. Academy of nutrition and dietetics: revised 2017 standards of practice and standards of professional performance for registered dietitian nutritionists (competent, proficient, and expert) in oncology nutrition. J Acad Nutr Diet. 2018;118:736-48.

10. Aggarwal A, Drewnowski A. Plant-and animal-protein diets in relation to sociodemographic drivers, quality, and cost: findings from the Seattle obesity study. Am J Clin Nutr. 2019; 110:451-60.
11. Darmon N, Drewnowski A. Contribution of food prices and diet cost to socioeconomic disparities in diet quality and health: a systematic review and analysis. Nutr Rev. 2015;73:643-60.

12. Limon-Miro AT, Lopez-Teros V, Astiazaran-Garcia H. Dynamic macronutrient meal-equivalent menu method: towards individual nutrition intervention programs. Methods Protoc. 2019;2:78.

13. World Medical Association. World medical association declaration of Helsinki: ethical principles for medical research involving human subjects. JAMA. 2013;310:2191-4.

14. Hagströmer M, Oja P, Sjöström M. The international physical activity questionnaire (IPAQ): a study of concurrent and construct validity. Public Health Nutr. 2006;9:755-62.

15. Castro-Vega I, Martín SV, Llorca JC, Vendrell CS, Bañuls C, Mijares $\mathrm{AH}$. Validation of nutritional screening malnutrition screening tool compared to other screening tools and the nutritional assessment in different social and health areas. Nutr Hosp. 2018;35:351-8.

16. Detsky AS, McLaughlin JR, Baker JP, Johnston N, Whittaker S, Mendelson RA, et al. What is subjective global assessment of nutritional status? JPEN J Parenter Enteral Nutr. 1987;11:8-13.

17. Perez-Lizaur AB Palacios-Gonzalez BP Castro-Becerra $A L$, Flores-Galicia I. SMAE: sistema mexicano de alimentos equivalentes SMAE: Mexican Equivalent Food System. 4th ed. Mexico: FNS; 2014

18. Central Bank of Mexico, BANXICO. Continuous Update Daily Exchange Rates Pesos per US Dollars 2020. Mexico: BANXICO; 2020. Available from: http://www.banxico.org.mx.

19. World Health Organization. Obesity: preventing and managing the global epidemic. Report of a WHO consultation. World Health Organ Tech Rep Ser. 2000;894:1-253.

20. Stewart A, Marfell-Jones M, International Society for Advancement of Kinanthropometry. International standards for anthropometric assessment. Lower Hutt, New Zealand: International Society for the Advancement of Kinanthropometry; 2011.

21. Heymsfield SB, McManus C, Smith J, Stevens V, Nixon DW. Anthropometric measurement of muscle mass: revised equations for calculating bone-free arm muscle area. Am J Clin Nutr. 1982:36:680-90.

22. World Cancer Research Fund/American Institute for Cancer Research. Continuous Update Project Expert Report 2018. Diet, Nutrition, Physical Activity and Breast Cancer. London: WCRF; 2018. Available form: http://www.dietandcancerreport.org.

23. Hicks C, Trickett A, Kwan YL, Ramanathan S. The use of adjusted ideal body weight for overweight patients undergoing HPC mobilisation for autologous transplantation. Ann Hematol. 2012;91:1795-801.

24. Valencia ME. Recomendaciones de ingestión de nutrimentos para la población mexicana: bases fisiológicas. In: Nutrient Intake Recommendations for Mexican Population: physiological Bases. Mexico: Editorial Médica Panamericana; 2009. p. 57-63.

25. Simone BA, Dan T, Palagani A, Jin L, Han SY, Wright C, et al. Caloric restriction coupled with radiation decreases metastatic burden in triple negative breast cancer. Cell Cycle. 2016;15: 2265-74.

26. Limon-Miro AT, Valencia ME, Lopez-Teros V, Guzman-Leon AE, Mendivil-Alvarado $\mathrm{H}$, Astiazaran-Garcia $\mathrm{H}$. Bioelectric impedance vector analysis (BIVA) in breast cancer patients: a tool for research and clinical practice. Medicina (Kaunas). 2019; 55:663.

27. Ferrer-Cascales R, Albaladejo-Blázquez $\mathrm{N}$, Ruiz-Robledillo $\mathrm{N}$ Clement-Carbonell V, Sánchez-SanSegundo M, Zaragoza-Martí A. Higher adherence to the Mediterranean diet is related to more subjective happiness in adolescents: the role of healthrelated quality of life. Nutrients. 2019;11:698.

28. Charan J, Biswas T. How to calculate sample size for different study designs in medical research? Indian J Psychol Med. 2013; 35:121-6.

29. Nishida C, Ko GT, Kumanyika S. Body fat distribution and noncommunicable diseases in populations: overview of the 2008 WHO expert consultation on waist circumference and waist-hip ratio. Eur J Clin Nutr. 2010;64:2-5.

30. Iwase T, Sangai T, Nagashima T, Sakakibara M, Sakakibara J, Hayama S, et al. Impact of body fat distribution on neoadjuvant chemotherapy outcomes in advanced breast cancer patients. Cancer Med. 2016;5:41-8.

31. Kobo O, Leiba R, Avizohar O, Karban A. Relative fat mass is a better predictor of dyslipidemia and metabolic syndrome than body mass index. Cardiovasc Endocrinol Metab. 2019;8:77-81.

32. Cederholm T, Barazzoni R, Austin P, Ballmer P, Biolo G, Bischoff SC, et al. ESPEN guidelines on definitions and terminology of clinical nutrition. Clin Nutr. 2017;36:49-64. 
33. Zorlini R, Abe Cairo AA, Gurgel MS. Nutritional status of patients with gynecologic and breast cancer. Nutr Hosp. 2008;23:577-83.

34. Chaves MR, Boléo-Tomé C, Monteiro-Grillo I, Camilo M, Ravasco P. The diversity of nutritional status in cancer: new insights. Oncologist. 2010;15:523-30.

35. Mohammadi S, Sulaiman S, Koon PB, Amani R, Hosseini SM. Association of nutritional status with quality of life in breast cancer survivors. Asian Pac J Cancer Prev. 2013;14:7749-55.

36. Rock CL, Doyle C, Demark-Wahnefried W, Meyerhardt J, Courneya KS, Schwartz AL, et al. Nutrition and physical activity guidelines for cancer survivors. CA Cancer J Clin. 2012;62: 243-74.
37. Cheng KK, Lim YT, Koh ZM, Tam WW. Home-based multidimensional survivorship programmes for breast cancer survivors. Cochrane Database Syst Rev. 2017;8:CD011152.

38. Hyder JA, Thomson CA, Natarajan L, Madlensky L, Pu M, Emond J, et al. Adopting a plant-based diet minimally increased food costs in WHEL study. Am J Health Behav. 2009;33:530-9.

39. Martinez S, Hand M, Da Pra M, Pollack S, Ralston K, Smith T, et al. Local Food Systems Concepts, Impacts, and Issues. 1st ed. United States: USDA; 2010.

40. Zhao A, Li Z, Ke Y, Huo S, Ma Y, Zhang Y, et al. Dietary diversity among Chinese residents during the COVID-19 outbreak and its associated factors. Nutrients. 2020;12:1699. 